\title{
Structure and Function of Stony Coral Intraskeletal Polysaccharides
}

Annamaria Naggi, ${ }^{*}{ }^{\dagger}$ Giangiacomo Torri, ${ }^{\dagger}$ Marcello Iacomini, ${ }^{\ddagger}$ Gabriele Colombo Castelli, ${ }^{\dagger}$ Michela Reggi, ${ }^{\S}$ Simona Fermani, ${ }^{\S}$ Zvy Dubinsky, $"$ Stefano Goffredo, ${ }^{*, \perp}$ and Giuseppe Falini*, ${ }^{\S}$

†Istituto di Ricerche Chimiche e Biochimiche “G. Ronzoni” Milano, via Giuseppe Colombo 81, 20133 Milano, Italy

${ }^{\ddagger}$ Departamento de Bioquímica e Biologia Molecular, Universidade Federal do Paraná, CP 19046, CEP 81531-980 Curitiba, Paraná, Brazil

${ }^{\S}$ Dipartimento di Chimica “Giacomo Ciamician”, Alma Mater Studiorum-Università di Bologna, via Selmi 2, 40126 Bologna, Italy

"The Mina \& Everard Goodman Faculty of Life Sciences, Bar-Ilan University, Ramat-Gan 5290002, Israel

${ }^{\perp}$ Marine Science Group, Department of Biological, Geological and Environmental Sciences, Alma Mater Studiorum-Università di Bologna, Via Selmi 3, 40126 Bologna, Italy

\section{Supporting Information}

ABSTRACT: Polysaccharides represent a main weight fraction of the intraskeletal organic matrix of corals, but their structure, as well as their function in the calcification process, has been poorly investigated. This communication shows by a combination of techniques (nuclear magnetic resonance, Fourier transform infrared, and monosaccharide composition) that their key component is a $1 \rightarrow 3 \beta$-D glucuronic acid polymer and evidences its influence in vitro in the calcification process.

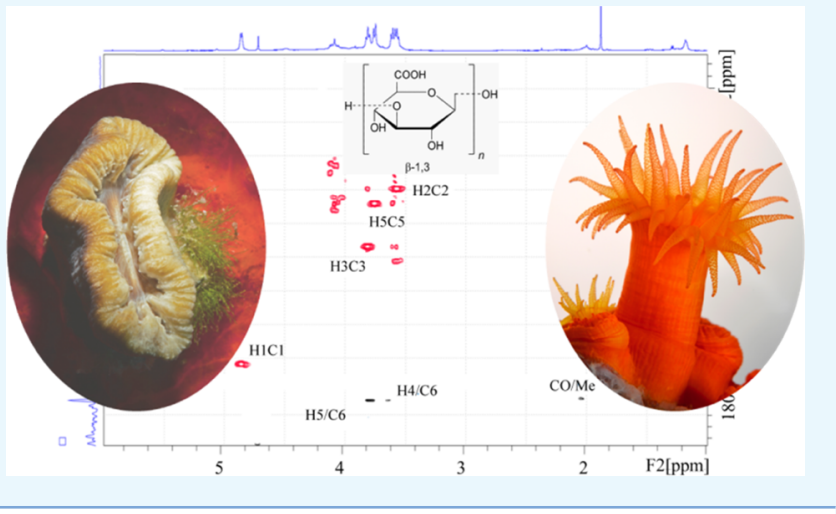

gen bonds with the surface of the growing crystals. ${ }^{18}$ That polysaccharides shield cation and anion trafficking to the crystals' surfaces inhibiting their growth. ${ }^{19}$

Usually, OM polysaccharides (pscOMs) bear sulfate groups ${ }^{20}$ that cooperate with the carboxylates one to induce $\mathrm{CaCO}_{3}$ nucleation. ${ }^{21,22}$ For instance, the investigation on the effects of carbohydrate additives during the early stages of $\mathrm{CaCO}_{3}$ precipitation revealed a variety of interaction between these additives and $\mathrm{CaCO}_{3}$ species, such as the complexation of $\mathrm{Ca}^{2+}$, the influence on the stability of solute prenucleation clusters, and the inhibition or promotion of nucleation. ${ }^{23}$ Giuffre et al. quantified the kinetics of calcite nucleation onto different polysaccharide substrates showing that polysaccharides with varying charge density, together with local supersaturation, regulate the mineral nucleation rate and density. ${ }^{24}$ Glycosaminoglycans and proteoglycans are also involved in biomineralization. ${ }^{22}$ For example, in chicken eggs, they control the morphology, the strength, and the thickness of the shells, ${ }^{25}$ and in crayfish gastrolith, they are closely associated with the inorganic mineral phase. ${ }^{26}$

Here, it is reported as the characterization of a fraction of pscOM from coral skeletons and the study of its influence on in

Received: December 23, 2017

Accepted: February 14, 2018

Published: March 9, 2018 
vitro $\mathrm{CaCO}_{3}$ precipitation. pscOM was obtained from the coral species, Astroides calycularis (Aca), Balanophyllia europaea (Beu), and Stylophora pistillata (Spi), which are representatives of diverse trophic strategies and growth forms. ${ }^{11}$

\section{RESULTS AND DISCUSSION}

pscOM was obtained by the mild alkaline digestion at room temperature of the whole intraskeletal OM (wOM, that is, soluble and insoluble fractions). Alkaline hydrolysis leads to the removal of saccharides which are O-linked to Ser or Thr and to the random breaking of peptide bonds in proteins, producing single amino acids or small peptides. Alkaline hydrolysis can also destroy monosaccharides and remove polysaccharide critical function groups (e.g., acetyl). ${ }^{27}$ This choice was carried out because protease activity by PNGase F (cleaving $N$-linked oligosaccharides at the $N$-glycosidic bond) and by other proteolitic enzymes having a broad specificity (see the Supporting Information), which was expected to hydrolyze the protein regions, failed. This is because their activity is restricted in the vicinity of densely glycosylated regions of the protein, presumably because of steric hindrance. ${ }^{28}$

The pscOM represents about 8 wt $\%$ of the wOM, with a great variability among different $(n=3)$ alkaline digestion experiments, more specifically: $7 \pm 4$ wt $\%$ for Aca, $8 \pm 4$ wt $\%$ for Beu, and $11 \pm 6$ wt $\%$ for Spi.

A first characterization of pscOM was performed by FTIR spectroscopy. In Figure 1, the most representative spectra of

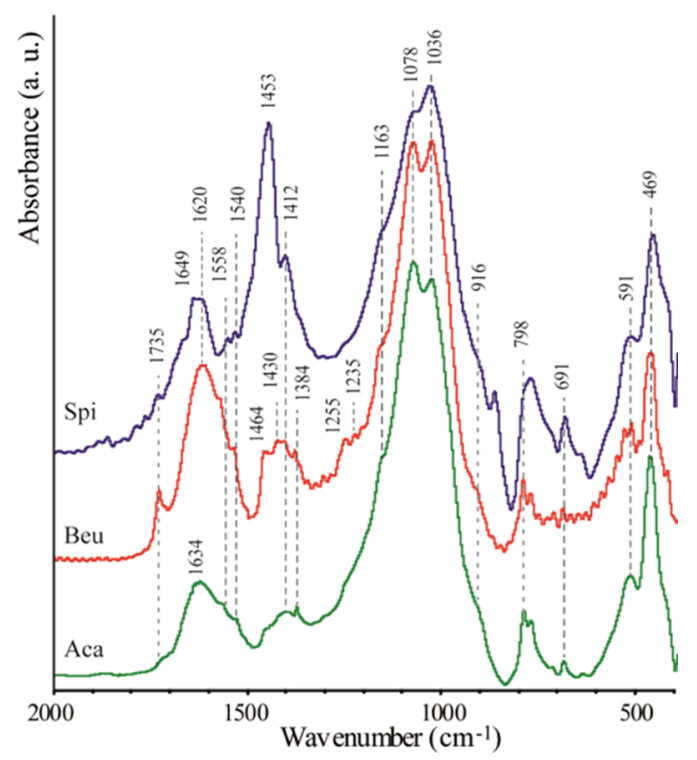

Figure 1. Fourier transform infrared (FTIR) spectra of intraskeletal polysaccharidic components of the OM extracted from skeleton of $A$. calycularis (Aca), B. europaea (Beu), and S. pistillata (Spi). The wavenumbers of the main absorption bands are indicated (FTIR spectra in the range $4000-400 \mathrm{~cm}^{-1}$ are reported in Figure S1).

pscOM for each species (small differences in absorption profiles were recorded among samples from the same species) are shown. A description of the assigned absorption bands is listed in Table $S 1 .{ }^{29,30}$ The relative intensities of these bands changed according to the pscOM source. The spectra from all of the species showed that the most intense bands were those because of polysaccharides $\left(1200-1000 \mathrm{~cm}^{-1}\right)$, namely the vibration modes associated with ring vibration overlapped with stretching vibrations of carbonyl group and the glycosidic bond vibration.
In particular, at 1078 and $1037 \mathrm{~cm}^{-1}$, ether bonds and $\mathrm{C}-\mathrm{C}$ single bond vibration modes were present. Weak absorption bands relative to methylene and methyl group vibration mode and to absorption bands at 1634 and $1649 \mathrm{~cm}^{-1}$ could be associated with the presence of both $\mathrm{N}$-acetyl and uronic acid residua. The FTIR spectrum of pscOM from Spi showed the presence of absorption bands at 1453 and $1412 \mathrm{~cm}^{-1}$ that were probably because of carboxylic groups. The pscOM from Beu showed additional weak bands at 1255 and $1235 \mathrm{~cm}^{-1}$ that can be associated with the $\mathrm{S}=\mathrm{O}$ stretching, suggesting the presence of sulfate groups.

The pscOM was further characterized by nuclear magnetic resonance (NMR) spectroscopy. The ${ }^{1} \mathrm{H}$ NMR pscOM spectrum of Spi was the most detailed one (Figure S2), whereas the other samples showed, despite the same purification process, large amount of broad signals suggesting the presence of different molecular components. The spectrum of Spi shows a predominant set of well-resolved signals coming into the typical chemical shift region of polysaccharides together with minor signals because of other minority components, as suggested by the FTIR spectrum. Mono- and bidimensional NMR techniques were used for the structure identification. Through 2D correlation spectroscopy (COSY) and total correlation spectroscopy (TOCSY), it was possible to identify the anomeric signal and four secondary alcohol signals belonging to the ring proton, whereas any $-\mathrm{CH}_{2}-$ or primary alcohol signals were detected. The investigation was prosecuted by heteronuclear ${ }^{1} \mathrm{H}-{ }^{13} \mathrm{C}$ COSY [heteronuclear singlequantum coherence (HSQC)] to verify the number of carbon atoms and to obtain the chemical shift values of their signals (Figure 2). The experiment confirmed the absence of diprotonated carbons suggesting the presence of a uronic acid residue. Using an NMR spectrometer equipped with cryoprobe, it was possible to perform a heteronuclear multiple bond correlation experiment (HMBC). The result of Spi NMR studies confirmed the working hypothesis of the presence of a uronic acid, identifying the three and two bond distances carbon-proton correlation, that is, the correlations of carboxyl in C6 with the protons of carbon 4 and 5 of the sugar ring. The assigned chemical shift values are reported in Table S2.

The proton and carbon chemical shift values of $\mathrm{C} 1, \mathrm{C} 3$, and C6 as well as the anomeric proton coupling constant $\left(J_{1-2}\right)$ indicate the presence of a $\beta 1-3$ glucuronic acid copolymer. The observed chemical shifts are in agreement with the literature data reporting a synthetic model obtained by oxidation of $(1 \rightarrow 3) \beta$-curdlan, in spite of the different spectrum calibration that cause a systematic 3 ppm shift in signals. ${ }^{32}$

Furthermore, experiments evidenced the presence of an $\mathrm{N}$ acetyl residue $\left({ }^{1} \mathrm{H}\right.$ : 2.02 ppm; ${ }^{13} \mathrm{C}$ : 25 and $\left.177 \mathrm{ppm}\right)$ likely linked to unidentified saccharidic minor component(s), whose detectable signals appear in the proton spectrum between 4.6 and $3.8 \mathrm{ppm}$ and having different anomeric signals at 5.52, 5.08, and $5.03 \mathrm{ppm}$.

The above data were supplemented by the analysis of constituent monosaccharides. In view of the presence of a polyglucuronate polymer, the Taylor and Conrad method was applied. ${ }^{33}$ Table 1 summarizes the results. The monosaccharide compositional pattern of pscOM from Aca, Beu, or Spi was similar; all extracts were extremely rich in glucuronic acid, which represented about 80 wt $\%$ of the total monosaccharides in each of these fractions. Arabinose, galactose, mannose, and xylose were also detected. 


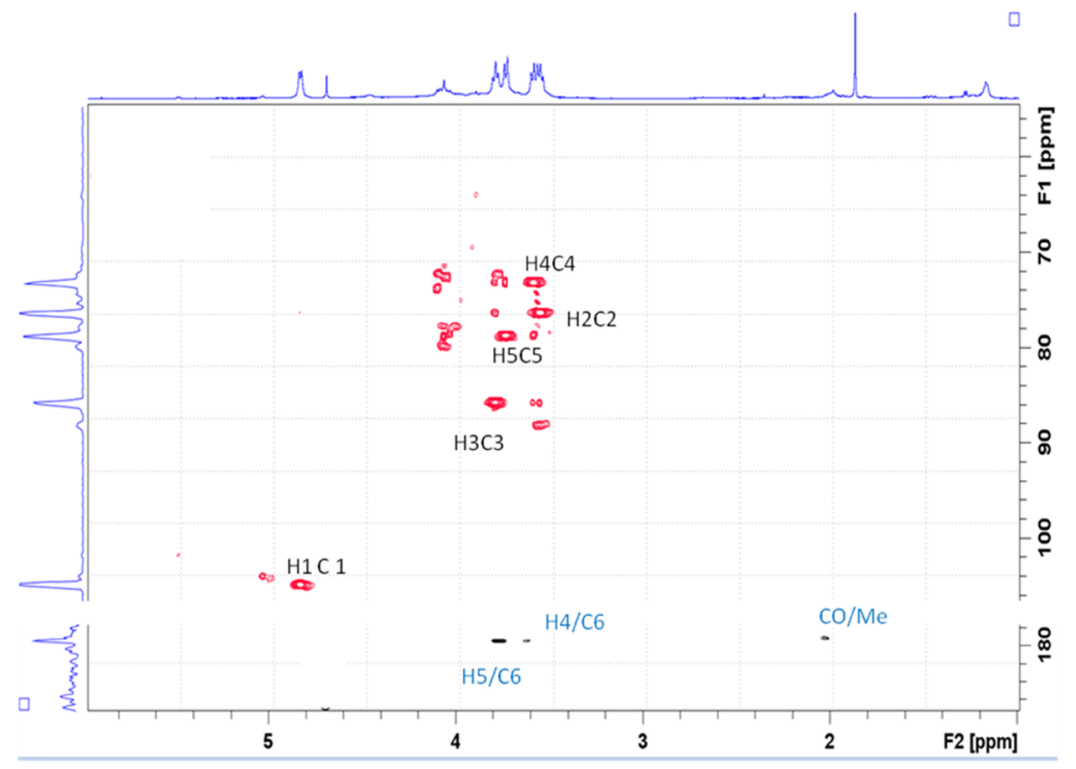

Figure 2. Combined HSQC (red) and HMBC (heteronuclear multiple bond correlation; black) partial spectra and spectral projections of $S$. pistillata. The assignment of major structure signals are reported in black, whereas the correlation peaks between carboxyl signal (C6) with proton 5 and 4 of glucuronic unit are marked in blue as well as that of an $\mathrm{N}$-acetyl residue. Homonuclear coupling in sensitivity-enhanced HSQC spectrum has generated a COSY effect. ${ }^{31}$ These correlation peaks, usually considered as artifacts, have been very useful in the assignments. Minor signal compatibles with carbohydrate structure(s) are present in the spectrum.

Table 1. Relative Molar Percentages of the Monosaccharide Detected in the pscOM from S. pistillata (Spi), B. europea (Beu), and $A$. calycularis (Aca)

\begin{tabular}{cccccc} 
& \multicolumn{5}{c}{ monosaccharide composition $(\%)^{a}$} \\
\cline { 2 - 6 } samples & Ara & Xyl & Man & Gal & Glc \\
Spi & 6.5 & 5.0 & 6.0 & 2.0 & 80.5 \\
Beu & 4.1 & 3.8 & 7.1 & 7.0 & 78.0 \\
Aca & 3.0 & 4.1 & 7.2 & 5.3 & 80.4
\end{tabular}

${ }^{a}$ Percentage of peak area relative to total peak areas, determined by GC-MS. Ara = arabinose; Man = mannose; Xyl = xylose; Gal = galactose; and Glc = glucose from glucuronic acid reduction (see Section 4.3.1, Monosaccharide Analysis).

The function of pscOM in the calcification process was investigated by in vitro calcium carbonate precipitation experiments. The presence of $\mathrm{pscOM}\left(0.27 \mathrm{mg} / \mathrm{cm}^{3}\right)$ partially inhibited the calcium carbonate deposition with respect to a control experiment free of pscOM (Figure S3), and it precipitated aggregates having diverse shapes and morphologies (Figure 3). Higher or lower pscOM concentrations provoked almost complete inhibition of precipitation or a reduced effect on particles shape and morphology, respectively. The FTIR spectra of these particles showed mainly the typical absorption bands of calcite, together with a band at around $1630 \mathrm{~cm}^{-1}$ assignable to polysaccharide and water (Figure S4). In the presence of pscOM from Aca, crystals of calcite appeared randomly aggregated in polycrystalline units that joined in big agglomerates (up to $\sim 150 \mu \mathrm{m}$ ) (Figure 3; Acal). Some insoluble components of the pscOM remained among the crystalline aggregates and glued them; indeed, they separated after bleaching. The aggregated calcite crystals almost completely lost the $\{10.4\}$ rhombohedral morphology and appeared edge-free (Figure 3; Aca2). The higher magnification image (Figure 3; Aca3) showed that the curved surfaces of the crystals were generated by the steps given by the combination of $\{10.4\}$ and $\{h k . l\}$ faces. Among the latter, the presence of small $\{00.1\}$ faces was identified (arrow in Figure 3; Aca2). The surfaces of the $\{10.4\}$ faces showed particles of about $200 \mathrm{~nm}$. In the presence of pscOM from Beu, calcitic spherulites having a diameter up to $180 \mu \mathrm{m}$ formed (Figure 3; Beu1). Their flat surface regions, associated with the $\{10.4\}$ faces, were surrounded by rough regions, associated with $\{h k . l\}$ faces. The latter was shown on the surface platelike particles of about $500 \mathrm{~nm}$ (Figure 3; Beu2-3). In the presence of pscOM from Spi, the rhombohedral calcite crystals clustered in aggregates having a diameter up to $150 \mu \mathrm{m}$ (Figure 3; Spi1). In these aggregates, calcite crystals compenetrated and preserved most of the $\{10.4\}$ faces. They also exposed $\{h k . l\}$ faces that smoothed the crystalline edges (Figure 3; Spil). The $\{10.4\}$ faces were very flat, whereas crystallites of about $100 \mathrm{~nm}$ were observed on the $\{h k . l\}$ faces.

The relevance of studying the structure of pscOM and their influence on the deposition of calcium carbonate in organisms are first given by their high relative mass content with respect to other macromolecules (i.e., proteins and lipids) into many calcified tissues. $^{1-4}$ This is particularly true for stony corals from the Mediterranean Sea, where their content was much higher than that of proteins. ${ }^{5}$ However, also other studies on tropical coral species provided a similar outcome. ${ }^{11,13}$

The pscOM investigated in this study represents only a fraction of the whole content of polysaccharides associated with the wOM. This is because the quite harsh treatment used for its extraction provoked the degradation and loss of sugars (not quantifiable). For that reason, its low mass content (about $8 \mathrm{wt}$ $\%)$ in the wOM is not in conflict with the $52 \mathrm{wt} \%$ of monosaccharides detected in the soluble OM from Acropora millepora. ${ }^{34}$ On the other side, the remaining material was still polymeric ( $\mathrm{MW}>3500 \mathrm{Da}$, according to dialysis) and of reduced complexity, making easier its structural characterization. Most importantly, its relevance for in vitro calcification studies is proved by the capability to affect the precipitation of calcium carbonate. 


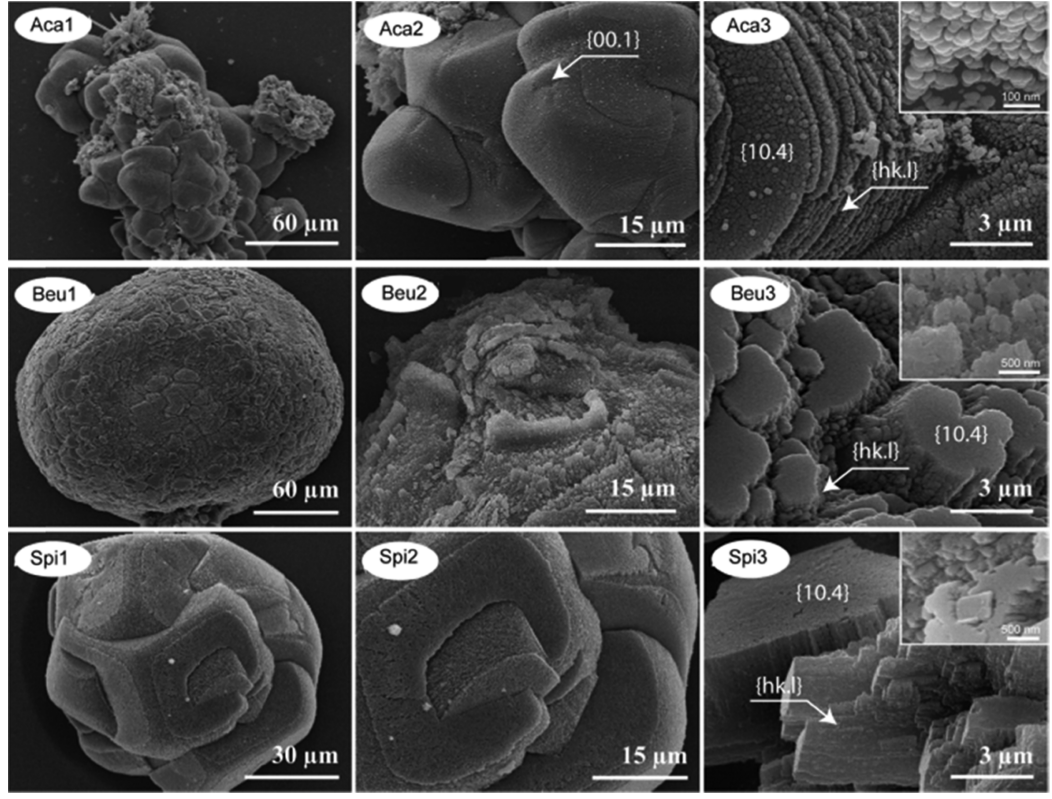

Figure 3. SEM pictures at increasing magnification (1-3) of crystals obtained from in vitro $\mathrm{CaCO}_{3}$ crystallization experiments from $10 \mathrm{mM} \mathrm{CaCl}{ }_{2}$ solution in the presence of pscOMs from A. calycularis (Aca), B. europaea (Beu), and S. pistillata (Spi). These pictures are the most representative of the populations of observed particles.

The monosaccharidic distribution of the pscOM from Aca, Beu, and Spi is similar (Table 1) and different from what was reported for other species of coral; $^{35,36}$ for example, in $A$. millepora, a content of about 70 wt $\%$ of arabinose and of about 3.9 wt \% of glucuronic acid was detected, but again, a diverse extraction procedure was used. The corals monosaccharidic composition is also diverse with most of sugar moieties associated with mollusks, where carbohydrates are quantitatively minor in comparison to proteins. ${ }^{37}$

In the case of Spi, the NMR investigations detected the presence of $1 \rightarrow 3 \quad \beta$-D glucuronic acid polymers. To our knowledge, this is the first identification of a polysaccharidic sequence in the OM of corals.

This signature is in line with what was observed in coccolithassociated polysaccharides. ${ }^{18,19}$ One of this polysaccharide, referred to as PS2, contains $\beta$-linked D-glucuronic acid sequences and has the role to accumulate calcium ions in the coccolith formation process. ${ }^{38}$ A coccolith contamination of our samples should be excluded because: (i) the skeletons were accurately observed by optical microscopy and did not show the presence of algae incrustations; (ii) the skeletons' X-ray powder diffraction patterns did not show diffraction peaks because of calcite, the mineral phase associate to coccoliths, but only aragonite; (iii) the relative high amount of $1 \rightarrow 3 \beta$-D glucuronic acid polymers in the pscOM composition cannot be justified by a contamination from cocooliths, which if present, should be below the detection limit of X-ray powder diffraction. Thus, the discovery that the pscOM contains $1 \rightarrow 3 \beta$-D glucuronic acid polymers may suggest a function in concentrating calcium ions, as occurring in coccoliths.

The presence of an $\mathrm{N}$-acetyl residue, linked to unidentified saccharide minor component(s), may indicate the presence of small amount of chitinlike structures, as already reported in old studies, ${ }^{16,17}$ which were resistant to the chemical treatment.

The function of polysaccharide on coral calcification is completely unknown, different from what was recently reported for proteins $^{6-12}$ and/or lipids. ${ }^{38}$
Here, the influence of $\mathrm{pscOM}$ on $\mathrm{CaCO}_{3}$ precipitation was studied by comparing the results of experiments performed in the presence of the pscOM, the wOM, and in the absence of additives. Without additives, only rhombohedral calcite crystals precipitated, whereas in the presence of pscOM, the morphologies observed were different from those imaged in the presence of wOM (Figure S5), according to their diverse composition (Figure 3).

Shape and morphology were different for particles formed in the presence of pscOM from the diverse species. In them, the observed morphology was generated by different crystal aggregation and the relative extension of $\{10.4\}$ and a-specific $\{h k . l\}$ stepping faces. However, in the presence of pscOM from Aca specific $\{00.1\}$ faces were observed. This face was observed in the calcite crystal grown in the presence of the polysaccharidic component of the OM extracted from the skeleton of the mollusk Atrina rigida and associated with the interaction with polysaccharidic moieties. ${ }^{39}$ In addition, the observation of diverse kind of nanoparticles (or crystal units) on the surface of the growing crystals agree with the recent observations that scleractinia coral skeleton forms through the aggregation of spherical particles of amorphous calcium carbonate. $^{6-12}$

These differences in the texture of the calcite crystals occur despite the similarity of the pscOM composition and the common presence, directly detected only for Spi, of $1 \rightarrow 3 \beta$-D glucuronic acid polymers. This observation is intriguing also considering that these scleractinia corals belong to diverse families, Beu and Aca to Dendrophylliidae, whereas Spi to Pocilloporidae.

In agreement with what was observed in the precipitation experiment of calcite, glucuronic acid concentrates and binds calcium ions ${ }^{38,40}$ and inhibits the nucleation process of calcium carbonate. $^{23}$ Interestingly, the capability of the glucuronic acid moieties to interact with calcium ions ${ }^{40}$ and calcite crystals ${ }^{22}$ is dependent on the way they are bonded to a polypeptide core. This feature also changes the assembly of calcite crystals from 
compenetrated units to spherulites, with a concomitant reduction of the size of monocrystals. ${ }^{41}$ This knowledge may justify the diverse calcite crystal shapes and textures observed in the presence of pscOM from different coral species.

\section{CONCLUSIONS}

In conclusion, in this study, for the first time, it is observed that $1 \rightarrow 3 \beta$-D glucuronic acid polymers are in the carbohydrate fraction of the wOM from corals. These polysaccharidic moieties can acts as calcite morphology modifiers in a species-specific manner. These discoveries shed a new light on the function of polysaccharide in the molecular processes which govern coral calcification.

\section{MATERIALS AND METHODS}

4.1. OM Extraction. The samples of B. europaea and $A$. calycularis from Palinuro (Italian coast, North-Western Mediterranean Sea) and S. pistillata from the Gulf of Eilat (Red Sea, Israel) were randomly collected by scuba diving at 6 , 9 , and $10 \mathrm{~m}$ depths, respectively. Coral skeletons were cleaned and ground, and wOM was extracted through decalcification using a $0.1 \mathrm{M}$ acetic acid solution, as previously reported. ${ }^{42}$ wOM was weighed and analyzed by FTIR spectroscopy using a Bruker ALPHA FTIR spectrometer equipped with a singlereflection diamond-attenuated total reflection accessory working in the range of wavenumbers $4000-400 \mathrm{~cm}^{-1}$ at a resolution of $4 \mathrm{~cm}^{-1}$.

4.2. Polysaccharide Purification. Protease digestion: 50 $\mathrm{mg}$ of wOM were dispersed in sodium phosphate buffer (100 $\mathrm{mM}, \mathrm{pH} 7.8,5 \mathrm{~mL}$ ). Pronase (protease type XIV from Streptomyces griseus, Sigma-Aldrich; $10 \mathrm{pg}$ ) was added and the solution was left for $24 \mathrm{~h}$ at $37^{\circ} \mathrm{C}$. Trypsin (Sigma-Aldrich; 50 $\mu \mathrm{g}$ ) was added and left for an additional $18 \mathrm{~h}$ at $37^{\circ} \mathrm{C}$. Then, the dispersion was extensively dialyzed against deionized water and finally lyophilized. PNGase F treatment: $50 \mathrm{mg}$ of wOM were dispersed in $5 \mathrm{~mL}$ of a denaturing $\mathrm{pH} 7.5,0.05 \mathrm{M}$ phosphate buffer containing $0.5 \mathrm{wt} \%$ sodium dodecyl sulfate and 1 wt $\%$ mercaptoethanol by heating at $100{ }^{\circ} \mathrm{C}$ for 2 min. PNGase F (20 units; Sigma-Aldrich) were added and incubated for $24 \mathrm{~h}$ at $37{ }^{\circ} \mathrm{C}$. The dispersion was extensively dialyzed against deionized water and finally lyophilized. Alkaline digestion: $50 \mathrm{mg}$ of $\mathrm{wOM}$ were dispersed in $5 \mathrm{~mL}$ of a 0.1 $\mathrm{M} \mathrm{NaOH}$ solution at room temperature and the resultant solution was stirred for 4 days at room temperature. Then, the dispersion was extensively dialyzed against deionized water and finally lyophilized and weighed.

The product of wOM enzymatic or chemical treatment was first characterized by FTIR spectroscopy. Only the alkaline digestion provoked a reduction of the proteic content, estimated by the intensity of FTIR absorption of the amide I and amide II proteic bands.

4.3. Polysaccharide Characterization. 4.3.1. Monosaccharide Analysis. The polysaccharide fraction from Spi, Beu, or Aca was carboxyl-reduced by the carbodiimide method, ${ }^{33}$ using two successive cycles to obtain reduced $\mathrm{CH}_{2} \mathrm{OH}$ from $\mathrm{COOH}$ groups of uronic acid units. $\mathrm{NaBH}_{4}$ was used as the reducing agent. Monosaccharide components of the carboxyl-reduced polysaccharide and their ratios were determined, following hydrolysis with $1 \mathrm{M}$ trifluoroacetic acid for $16 \mathrm{~h}$ at $100{ }^{\circ} \mathrm{C}$. The acid was then evaporated, and the residue was dissolved in water. The hydrolyzate was converted to alditol acetates by treatment with $\mathrm{NaBH}_{4}$, followed by acetylation with acetic anhydride-pyridine $(1: 1 \mathrm{v} / \mathrm{v})$ at $100{ }^{\circ} \mathrm{C}$ for $30 \mathrm{~min}$, and the resulting alditol acetates were extracted with chloroform. The alditol acetate analysis was carried out using a Varian gas chromatograph, model CP-3800, and mass spectrometer, model Saturn 4000R, with $\mathrm{He}$ as the carrier gas $(1 \mathrm{~mL} / \mathrm{min})$. A capillary column $(30 \mathrm{~m} \times 0.25 \mathrm{~mm}$ i.d. $)$ of DB-1, held at 100 ${ }^{\circ} \mathrm{C}$ during injection for $1 \mathrm{~min}$, then programmed at $5{ }^{\circ} \mathrm{C} / \mathrm{min}$ to $220{ }^{\circ} \mathrm{C}$, and held at $280{ }^{\circ} \mathrm{C}$ for $18 \mathrm{~min}$ was used for the quantitative analysis. The alditol acetates were identified by their retention times and typical electron impact breakdown profiles compared with standards.

4.3.2. NMR Characterization. The product of the alkaline digestion was characterized by NMR spectroscopy. NMR spectra were recorded at $25{ }^{\circ} \mathrm{C}$ using Bruker AVANCE III spectrometers (600 and $500 \mathrm{MHz}$ ) equipped with highsensitivity $5 \mathrm{~mm}$ TCI cryoprobes. After exchanging $2 \mathrm{mg}$ of the sample thrice in ${ }^{2} \mathrm{H}_{2} \mathrm{O}$, samples were dissolved in $0.6 \mathrm{~mL}$ of a $3 \mathrm{mM}$ EDTA $d_{6}{ }^{2} \mathrm{H}_{2} \mathrm{O}(99.996 \%)$ solution and placed in 5 $\mathrm{mm}$ NMR tubes. Proton spectra were recorded with presaturation of the residual water signal with a recycle delay of $6 \mathrm{~s}$ and 32 scans. Bidimensional DQF (double-quantumfilter)-COSY and 2D (two dimensional)-TOCSY spectra were acquired using 16 scans per series of $2048 \times 256$ data points with zero-filling in F1 $(4096 \times 1024)$, and a shifted $(\pi /$ 3) squared cosine function was applied prior to Fourier transformation. HSQC and HMBC (heteronuclear multiple bond correlation) spectra were obtained in phase-sensitivityenhanced pure-absorption mode with decoupling in the acquisition period. Scans (40 and 96) were collected for each free-induction decay. The matrix size of $1024 \times 320$ data points was zero-filled to $4096 \times 1024$ by the application of a squared cosine function prior to Fourier transformation.

4.4. Calcium Carbonate Crystallization Experiments. Calcium carbonate $\left(\mathrm{CaCO}_{3}\right)$ in vitro crystallization experiments were carried out by vapor diffusion in a desiccator containing $\left(\mathrm{NH}_{4}\right)_{2} \mathrm{CO}_{3}$ (Carlo Erba) and anhydrous $\mathrm{CaCl}_{2}$ (Sigma-Aldrich). Microplates for cellular culture (Microplate 24 well with lid, Iwaki), containing a round glass coverslip in each well, were used as previously reported. ${ }^{42} \mathrm{CaCl}_{2}$ solutions $(750$ $\mu \mathrm{L}$ of $10 \mathrm{mM} ; \mathrm{CaCl}_{2} 2 \mathrm{H}_{2} \mathrm{O}$, Sigma-Aldrich) were poured in each well. wOM $(0.2 \mathrm{mg})$ or pscOM $(0.2 \mathrm{mg})$ were added in some well. This concentration $(0.27 \mathrm{mg} / \mathrm{mL})$ ensured the optimal precipitation yield having a change of the particle's shape and morphology. Microplates were located in the desiccator for 4 days at room temperature. The obtained crystals were washed with distilled water and dried. $\mathrm{CaCO}_{3}$ crystallization experiments were replicated at least five times.

Characterization of $\mathrm{CaCO}_{3}$ precipitates was carried out by FTIR spectroscopy and microscopic observations. FTIR spectra of samples in $\mathrm{KBr}$ disks were collected at room temperature by using a Bruker ALPHA FTIR spectrometer working in the range of $4000-400 \mathrm{~cm}^{-1}$ at a resolution of $4 \mathrm{~cm}^{-1}$. Optical microscopic observations of $\mathrm{CaCO}_{3}$ precipitates were carried out using a Leica microscope equipped with a digital camera. SEM observations were conducted using a Hitachi FEG 6400 scanning electron microscope after coating the samples with gold.

\section{ASSOCIATED CONTENT}

\section{Supporting Information}

The Supporting Information is available free of charge on the ACS Publications website at DOI: 10.1021/acsomega.7b02053. 
Characterization data; ${ }^{1} \mathrm{H}$ NMR spectra; FTIR spectra; and SEM images (PDF)

\section{AUTHOR INFORMATION}

\section{Corresponding Authors}

*E-mail: naggi@ronzoni.it (A.N.).

*E-mail: s.goffredo@unibo.it (S.G.).

*E-mail: giuseppe.falini@unibo.it (G.F.).

\section{ORCID}

Giuseppe Falini: 0000-0002-2367-3721

\section{Notes}

The authors declare no competing financial interest.

\section{ACKNOWLEDGMENTS}

G.F. and S.F. thank the Centro Inter Universitario di Ricerca per la Chimica dei Metalli nei Sistemi Biologici. We thank Francesco Suppo for the underwater camera pictures of $B$. europaea and A. calycularis.

\section{REFERENCES}

(1) Weiner, S.; Addadi, L. Design strategies in mineralized biological materials. J. Mater. Chem. 1997, 7, 689.

(2) Muscatine, L.; Goiran, C.; Land, L.; Jaubert, J.; Cuif, J.-P.; Allemand, D. Stable isotopes (delta C-13 and delta N-15) of organic matrix from coral skeleton. Proc. Natl. Acad. Sci. U.S.A. 2005, 102, 1525.

(3) Tambutté, S.; Holcomb, M.; Ferrier-Pagès, C.; Reynaud, S.; Tambutté, É.; Zoccola, D.; Allemand, D. Coral biomineralization: From the gene to the environment. J. Exp. Mar. Biol. Ecol. 2011, 408, 58.

(4) Cuif, J. P.; Dauphin, Y.; Freiwald, A.; Gautret, P.; Zibrowius, H. Biochemical markers of zooxanthellae symbiosis in soluble matrices of skeleton of 24 Scleractinia species. Comp. Biochem. Physiol., Part A: Mol. Integr. Physiol. 1999, 123, 269.

(5) Adamiano, A.; Goffredo, S.; Dubinsky, Z.; Levy, O.; Fermani, S.; Fabbri, D.; Falini, G. Analytical pyrolysis-based study on intra-skeletal organic matrices from Mediterranean corals. Anal. Bioanal. Chem. 2014, 406, 6021.

(6) Von Euw, S.; Zhang, Q.; Manichev, V.; Murali, N.; Gross, J.; Feldman, L. C.; Gustafsson, T.; Flach, C.; Mendelsohn, R.; Falkowski, P. G. Biological control of aragonite formation in stony corals. Science 2017, 356, 933.

(7) Mass, T.; Drake, J. L.; Heddleston, J. M.; Falkowski, P. G. Nanoscale Visualization of Biomineral Formation in Coral ProtoPolyps. Curr. Biol. 2017, 27, 3191.

(8) Mass, T.; Putnam, H. M.; Drake, J. L.; Zelzion, E.; Gates, R. D.; Bhattacharya, D.; Falkowski, P. G. Temporal and spatial expression patterns of biomineralization proteins during early development in the stony coral Pocillopora damicornis. Proc. R. Soc. Ser. B 2016, 283, 20160322

(9) Sun, C.-Y.; Marcus, M. A.; Frazier, M. J.; Giuffre, A. J.; Mass, T.; Gilbert, P. U. P. A. Spherulitic Growth of Coral Skeletons and Synthetic Aragonite: Nature's Three-Dimensional Printing. ACS Nano 2017, 11, 6612 .

(10) Mass, T.; Giuffre, A. J.; Sun, C.-Y.; Stifler, C. A.; Frazier, M. J.; Neder, M.; Tamura, N.; Stan, C. V.; Marcus, M. A.; Gilbert, P. U. P. A. Amorphous calcium carbonate particles form coral skeletons. Proc. Natl. Acad. Sci. U.S.A. 2017, 114, No. E7670.

(11) Falini, G.; Fermani, S.; Goffredo, S. Coral biomineralization: A focus on intra-skeletal organic matrix and calcification. Semin. Cell Dev. Biol. 2015, 46, 17.

(12) Constantz, B.; Weiner, S. Acidic macromolecules associated with the mineral phase of scleractinian coral skeletons. J. Exp. Zool. 1988, $248,253$.

(13) Cuif, J.-P.; Dauphin, Y.; Gautret, P. Compositional diversity of soluble mineralizing matrices in some recent coral skeletons compared to fine-scale growth structures of fibres: discussion of consequences for biomineralization and diagenesis. Int. J. Earth Sci. 1999, 88, 582.

(14) Weiner, S.; Addadi, L. Crystallization Pathways in Biomineralization. Annu. Rev. Mater. Res. 2011, 41, 21.

(15) Addadi, L.; Joester, D.; Nudelman, F.; Weiner, S. Mollusk Shell Formation: A Source of New Concepts for Understanding Biomineralization Processes. Chem.-Eur. J. 2006, 12, 980.

(16) Wainwright, S. A. Skeletal organization in the coral, Pocillopora. J. Cell Sci. 1963, s3-104, 169.

(17) Young, S. D. Organic material from scleractinian coral skeletons: 1. Variation in composition between several species. Comp. Biochem. Physiol., Part B: Biochem. Mol. Biol. 1971, 40, 113.

(18) Young, J. R.; Henriksen, K. Biomineralization within vesicles: the calcite of coccoliths. Rev. Mineral. Geochem. 2003, 54, 189.

(19) Yang, M.; Stipp, S. L. S.; Harding, J. Biological Control on Calcite Crystallization by Polysaccharides. Cryst. Growth Des. 2008, 8, 4066.

(20) Cuif, J.-P.; Dauphin, Y.; Doucet, J.; Salome, M.; Susini, J. XANES mapping of organic sulfate in three scleractinian coral skeletons. Geochim. Cosmochim. Acta 2003, 67, 75.

(21) Addadi, L.; Moradian, J.; Shay, E.; Maroudas, N. G.; Weiner, S. A chemical model for the cooperation of sulfates and carboxylates in calcite crystal nucleation: Relevance to biomineralization. Proc. Natl. Acad. Sci. U.S.A. 1987, 84, 2732.

(22) Arias, J. L.; Fernández, M. S. Polysaccharides and Proteoglycans in Calcium Carbonate-based Biomineralization. Chem. Rev. 2008, 108, 4475.

(23) Rao, A.; Berg, J. K.; Kellermeier, M.; Gebauer, D. Sweet on biomineralization: Effects of carbohydrates on the early stages of calcium carbonate crystallization. Eur. J. Mineral. 2014, 26, 537.

(24) Giuffre, A. J.; Hamm, L. M.; Han, N.; De Yoreo, J. J.; Dove, P. M. Polysaccharide chemistry regulates kinetics of calcite nucleation through competition of interfacial energies. Proc. Natl. Acad. Sci. U.S.A. 2013, 110, 9261.

(25) Ha, Y. W.; Son, M. J.; Yun, K. S.; Kim, Y. S. Relationship between eggshell strength and keratan sulfate of eggshell membranes. Comp. Biochem. Physiol., Part A: Mol. Integr. Physiol. 2007, 147, 1109.

(26) Fernández, M. S.; Bustos, C.; Luquet, G.; Saez, D.; NeiraCarrillo, A.; Corneillat, M.; Alcaraz, G.; Arias, J. L. Proteoglycan occurrence in gastrolith of the crayfish Cherax quadricarinatus (Crustacea, Malacostraca, Decapoda). J. Crustacean Biol. 2012, 32, 802.

(27) Carlson, D. M. Structures and immunochemical properties of oligosaccharides isolated from pig submaxillary mucins. J. Biol. Chem. 1968, 243, 616-626.

(28) Lechner, J.; Wieland, E. Methods in Molecular Biology; Hounsell, E. F., Ed.; Humana: Totowa, 1993; Vol. 14.

(29) Marxen, J. C.; Hammer, M.; Gehrke, T.; Becker, W. Carbohydrates of the Organic Shell Matrix and the Shell-Forming Tissue of the Snail Biomphalaria glabrata (Say). Biol. Bull. 1998, 194, 231.

(30) Synytsya, A.; Kim, W.-J.; Kim, S.-M.; Pohl, R.; Synytsya, A.; Kvasnička, F.; Copíková, J.; Il Park, Y. Structure and antitumour activity of fucoidan isolated from sporophyll of Korean brown seaweed Undaria pinnatifida. Carbohydr. Polym. 2010, 81, 41.

(31) Turner, C. J.; Connolly, P. J.; Stern, A. S. Artifacts in sensitivityenhanced HSQC. J. Magn. Reson. 1999, 137, 281.

(32) Delattre, C.; Rios, L.; Laroche, C.; Le, N. H. T.; Lecerf, D.; Picton, L.; Berthon, J. Y.; Michaud, P. Production and characterization of new families of polyglucuronic acids from TEMPO-NaOCl oxidation of curdlan. Int. J. Biol. Macromol. 2009, 45, 458.

(33) Taylor, R. L.; Conrad, H. E. Stoichiometric depolymerization of polyuronides and glycosaminoglycuronans to monosaccharides following reduction of their carbodiimide-activated carboxyl group. Biochemistry 1972, 11, 1383.

(34) Ramos-Silva, P.; Kaandorp, J.; Herbst, F.; Plasseraud, L.; Alcaraz, G.; Stern, C.; Corneillat, M.; Guichard, N.; Durlet, C.; Luquet, G.; Marin, F. The Skeleton of the Staghorn Coral Acropora millepora: Molecular and Structural Characterization. PLoS One 2014, 9, No. e97454. 
(35) Gautret, P.; Cruit, J.-P.; Freiwald, A. Composition of soluble mineralizing matrices in zooxanthellate and non-zooxanthellate scleractinian corals: Biochemical assessment of photosynthetic metabolism through the study of a skeletal feature. Facies 1997, 36, 189.

(36) Marin, F.; Luquet, G. Molluscan shell proteins. Comptes Rendus Palevol 2004, 3, 469.

(37) Lee, R. B. Y.; Mavridou, D. A. I.; Papadakos, G.; McClelland, H. L. O.; Rickaby, R. E. M. The uronic acid content of coccolithassociated polysaccharides provides insight into coccolithogenesis and past climate. Nat. Commun. 2016, 7, 13144.

(38) Reggi, M.; Fermani, S.; Samorì, C.; Gizzi, F.; Prada, F.; Dubinsky, Z.; Goffredo, S.; Falini, G. Influence of intra-skeletal coral lipids on calcium carbonate precipitation. CrystEngComm 2016, 18, 8829.

(39) Albeck, S.; Weiner, S.; Addadi, L. Polysaccharides of Intracrystalline Glycoproteins Modulate Calcite Crystal Growth In Vitro. Chem.-Eur. J. 1996, 2, 278.

(40) Woodward, C.; Davidson, E. A. Structure-function relationships of protein polysaccharide complexes: specific ion-binding properties. Proc. Natl. Acad. Sci. U.S.A. 1968, 60, 201.

(41) Braissant, O.; Cailleau, G.; Dupraz, C.; Verrecchia, E. P. Bacterially induced mineralization of calcium carbonate in terrestrial environments: the role of exopolysaccharides and amino acids. $J$. Sediment. Res. 2003, 73, 485.

(42) Falini, G.; Reggi, M.; Fermani, S.; Sparla, F.; Goffredo, S.; Dubinsky, Z.; Levi, O.; Dauphin, Y.; Cuif, J.-P. Control of aragonite deposition in colonial corals by intra-skeletal macromolecules. J. Struct. Biol. 2013, 183, 226. 